\title{
ПРАВО ПУБЛИЧНЫХ СОБРАНИЙ В СОВРЕМЕННОЙ РОССИИ: КОНСТИТУЦИОННЫЕ ОСНОВЫ И ПРОБЛЕМЫ РЕАЛИЗАЦИИ
}

\section{І. Предисловие}

Несомненным фактом является то, что в современной Российской Федерации идёт активное развитие законодательства о свободе собраний, а также существует богатая и весьма неоднозначная правоприменительная практика в данной сфере. В России и за рубежом широкую известность получило множество гражданских инициатив так или иначе связанных с борьбой за защиту права на организацию и проведение публичных мероприятий. Так, в середине 2009 года было основано всероссийское гражданское движение в защиту свободы собраний в России под названием «Стратегия 31», главной целью которого стало привлечение общественного внимания к проблемам реализации гражданами статьи 31 конституции РФ (т.е. конституционного права на свободу собраний). ${ }^{3}$ Организаторы «Стратегии 31» выбрали оригинальный способ для выражения своих взглядов и требований: проведение регулярных манифестаций 31 числа каждого месяца, в котором есть такая дата. Помимо данной инициативы в России на протяжении 2009-2012 гг. можно было наблюдать увеличение протестной активности в целом по стране, которая началась в калининграде (митинги 2009-2012 гг.) $)^{4}$ и кульминацией которой стали многотысячные акции простеста в Москве (например, 24.12.2011 года на проспекте

1 E-mail: alexander.salenko@gmail.com

2 Данная статья подготовлена в рамках научно-исследовательского проекта на факультете права университета города Белосток, финансируемого фондом поддержки науки / фрондом имени И. Мяновского (Jozef Mianowski Fund / A Foundation for the Promotion of Science). Автор статьи выражает свою благодарность коллегам на факультете права в Белостоке, а также сотрудникам фонда Мяновского за их поддержку и поддержку во время работы над данным материалом.

3 Стратегия 31. За свободу собраний! http://31svoboda.livejournal.com/

4 Александр Саленко. Янтарная революция. RUGRAD.EU. 24.02.2010. http://rugrad.eu/communication/blogs/ Magister/1013/ 
имени академика Сахарова). ${ }^{5}$ Есть множество других фактов, убедительно свидетельствующих об актуальности рассматриваемой темы: протестные акции общества «синих ведёрок» ${ }^{6}$, выезд граждан для политического протеста за границу (например, акция калининградских активистов в Гданьске) ${ }^{7}$ и даже трагикомичная история с запретом «несанкционированного чаепития» в городе Новороссийск. ${ }^{8}$ Пожалуй апогеем в данном контексте является история с организацией «наномитингов», когда в ответ на фактический запрет публичного мероприятия в Барнауле его организаторы провели «игрушечный митинг», участие в котором принимали не люди, а детские куклы, снабжённые лозунгами с политическими требованиями. В 2012 году волна «наномитингов» прокатилась по другим городам России: Омск, Иркутск, Апатиты, Улан-Удэ и Санкт-Петербург. ${ }^{9}$

В связи с нарастающей протестной активностью были предприняты ответные действия российских властей. В середине 2012 года вступили в силу поправки в федеральное законодательство о свободе собраний, которые значительно увеличили ответственность за нарушение порядка организации и проведения собраний, митингов, демонстраций, шествий и пикетирования. В данной статье предпринята попытка проанализировать действующее российское законодательство о свободе собраний, в частности произвести разбор нововведений в закон о митингах и шествиях 2012 года, а также выявить и исследовать существующие проблемы правоприменительной практики при организации и проведении публичных мероприятий.

\section{II. Правовое регулирование публичных собраний в России}

В рамках российской правовой системы основополагающим нормативным правовых актом, регулирующего право публичных собраний, является конституция Российской Федерации (статья 31), которая закрепляет право граждан собираться мирно, без оружия, проводить собрания, митинги, демонстрации, шествия и пикетирование. кроме того, конституция России допускает существование определённых ограничений, устанавливаемых федеральным законом только в той мере, в какой это необходимо для защиты основ конституцион-

5 Проспект Сахарова 24 декабря: интерактивная панорама. РИА НОВОСТИ. 27.12.2011. http://ria.ru/ infografika/20111227/527721415.html

6 Сергей Пархоменко. В Москве автомобилисты протестовали против спецсигналов. ГРАНИ.РУ. 18.04.2010. http://grani.ru/Society/Law/m.177181.html

7 Оппозиция в калининграде хочет перенести акции протеста на территорию соседней Польши. ИНТЕРФАкС РОССИЯ. 07.06.2012. http://www.interfax-russia.ru/NorthWest/main.asp?id=320262

8 В Новороссийске правозащитников осудили за несанкционированное чаепитие. ГРАНИ.РУ. 06.02.2007. http://grani.ru/Events/m.117798.html

9 Сергей Тепляков. Игрушкам отказали в наномитинге. ГАЗЕTA.RU. 14.02.2012. http://www.gazeta.ru/ politics/2012/02/14_kz_4000753.shtml 
ного строя, нравственности, здоровья, прав и законных интересов других лиц, обеспечения обороны страны и безопасности государства (часть 3 статьи 55). В соответствии с пунктом «к» части 1 статьи 72 конституции РФ правовое регулирование права публичных собраний находится в совместном ведении Российской Федерации и субъектов Российской Федерации.

Федеральный закон от 19 июня 2004 года №54-Ф3 «О собраниях, митингах, демонстрациях, шествиях и пикетированиях» (далее, как федеральный закон о митингах или Ф3 №54) может быть обозначен в качестве lex specialis в данной сфере правового регулирования. ${ }^{10}$ При этом данный федеральный закон неоднократно упоминает о возможности и необходимости принятия соответствующих законов субъектов Российской Федерации, касающиеся обеспечения условий проведения собраний, митингов, демонстраций, шествий и пикетирований (например, часть 1 статьи 1, часть 1.1 статьи 7). Таким образом, следует ожидать, что в ближайшее время региональные законодательные (представительные) органы власти начнут работу над специальными законами субъектов Российской Федерации, регулирующими порядок проведения публичных мероприятий на уровне отдельного субъекта федерации.

В соответствии с федеральныл законом о митингах организатором публичного мероприятия могут быть один или несколько граждан России (организатором демонстраций, шествий и пикетирований - гражданин России, достигший возраста 18 лет, митингов и собраний - 16 лет), политические партии, другие общественные объединения и религиозные объединения, их региональные отделения и иные структурные подразделения, взявшие на себя обязательство по организации и проведению публичного мероприятия (часть 1 статьи 5 Ф3 №54). Согласно закону в качестве предпосылки проведения публичного мероприятия предусматривается уведомление, которое подается его организатором в письменной форме в орган исполнительной власти субъекта Российской Федерации или орган местного самоуправления в срок не ранее 15 и не позднее 10 дней до дня проведения публичного мероприятия. При проведении пикетирования группой лиц уведомление о проведении публичного мероприятия может подаваться в срок не позднее трех дней до дня его проведения, а если указанные дни совпадают с воскресеньем и (или) нерабочим праздничным днем (нерабочими праздничными днями), - не позднее четырех дней до дня его проведения. Закон о митингах предусматривает, что уведомление о пикетировании, осуществляемом одним участником, не требуется. Федеральный законодатель закрепил особую правовую категорию - «минимальное допустимое расстояние между лицами, осуществляющими одиночное пикети-

10 Федеральный закон от 19.06.2004 N 54-Ф3 (редакция от 08.06.2012) «О собраниях, митингах, демонстрациях, шествиях и пикетированиях» // СПС «консультант плюс». 
рование», которое должно определяться законом субъекта Российской Федерации. Однако согласно ФЗ №54 данное минимальное расстояние не может быть более пятидесяти метров.

\section{III. Новеллы в законодательстве о свободе собраний в России 2012 года}

9 июня 2012 года вступили в силу поправки в административное законодательство России, которое регламентирует порядок организации и проведения публичных собраний, а также ответственно организаторов массовых мероприятий, проводимых в Российской Федерации. ${ }^{11}$ Вне всякого сомнения плоды законотворческой работы Парламента Российской Федерации привлекли к себе значительное общественное внимание как в России, так и за рубежом. Попытаемся систематизировать произошедшие изменения в законодательстве о свободе собраний в России.

Во-первых, в законе о митингах появился чёткий запрет, адресованный участникам массовых мероприятий, скрывать свое лицо, в том числе использовать маски, средства маскировки, иные предметы, специально предназначенные для затруднения установления личности (часть 4 статьи 6 Ф3 №54). ${ }^{12}$ Вне всякого сомнения подобная законодательная новелла давно уже была необходима в российском законе о митингах. Однако, законодатель оставил вне пределов своего внимания аналогичную проблему, связанную с потребностью в идентификации полицейских принимающих участие в массовых мероприятий. В случае неоправданного применения силы со стороны сотрудников полиции должна также иметься реальная возможность идентификации полицейского-правонарушителя (при помощи чётко различимых номеров на униформе полицейских, размещаемых, например, на спине сотрудника полиции). Подобное правовое регулирование существуют в зарубежном законодательстве, в частности в ФРГ, где сотрудник полиции выбирает по своему усмотрению, что будет использовано на его униформе: цифровая идентификация или указание фамилии имени отчества.

11 Федеральный закон Российской Федерации от 8 июня 2012 г. N 65-Ф3 г. «О внесении изменений в кодекс Российской Федерации об административных правонарушениях и Федеральный закон «О собраниях, митингах, демонстрациях, шествиях и пикетированиях» // Российская газета (федеральный выпуск №5804). 9 июня 2012 года. http://www.rg.ru/2012/06/09/mitingi-dok.html

12 Помимо этого в законодательство о свободе собраний были включены запреты находиться в месте проведения публичного мероприятия в состоянии опьянения, иметь при себе и (или) распивать алкогольную и спиртосодержащую продукцию, пиво и напитки, изготавливаемые на его основе, а также запрет иметь при себе оружие или предметы, используемые в качестве оружия, взрывчатые и легковоспламеняющиеся вещества (ч.4 ст.6 Ф3 №54). кроме того был предусмотрен запрет участвовать в организации публичных мероприятий лицам, имеющим неснятую или непогашенную судимость за совершение умышленного преступления против основ конституционного строя и безопасности государства или преступления против общественной безопасности и общественного порядка либо два и более раза привлекавшееся к административной ответственности за определённые административные правонарушения. 
Во-вторых, значительно была увеличена ответственность организаторов и участников массовых мероприятий за нарушение законодательства о свободе собраний. В частности, в кодексе об административных правонарушениях (КоАП) появились новые статьи: статья 3.13, статья 20.2 КоАП была изложена в новой редакции и кодекс был дополнен статьёй $20.2^{2}$.

Обновлённая статья 20.2 КоАП содержит концентрированную подборку мер административной ответственности за нарушение установленного порядка организации либо проведения собрания, митинга, демонстрации, шествия или пикетирования. С помощью нижеследующей таблицы №1 попытаемся оценить плюсы и минусы предложенного правового регулирования административной ответственности за нарушение закона при организации и проведении публичных мероприятий.

\section{Таблица №1}

\begin{tabular}{|c|c|}
\hline \multicolumn{2}{|c|}{ статья 20.2 КоАП } \\
\hline Диспозиция & санкция \\
\hline \multicolumn{2}{|c|}{ ответственность организаторов публичного мероприятия } \\
\hline $\begin{array}{l}\text { 1. Нарушение организатором публичного } \\
\text { мероприятия установленного порядка } \\
\text { организации либо проведения собрания, } \\
\text { митинга, демонстрации, шествия или } \\
\text { пикетирования, за исключением случаев, } \\
\text { предусмотренных частями } 2 \text { - } 4 \text { настоящей } \\
\text { статьи, - }\end{array}$ & $\begin{array}{l}\text { влечет наложение административного штрафа } \\
\text { на граждан в размере от десяти тысяч до } \\
\text { двадцати тысяч рублей или обязательные } \\
\text { работы на срок до сорока часов; на } \\
\text { должностных лиц - от пятнадцати тысяч до } \\
\text { тридцати тысяч рублей; на юридических лиц - } \\
\text { от пятидесяти тысяч до ста тысяч рублей. }\end{array}$ \\
\hline $\begin{array}{l}\text { 2. Организация либо проведение публичного } \\
\text { мероприятия без подачи в установленном } \\
\text { порядке уведомления о проведении } \\
\text { публичного мероприятия, за исключением } \\
\text { случаев, предусмотренных частью } 7 \\
\text { настоящей статьи, - }\end{array}$ & $\begin{array}{l}\text { влечет наложение административного штрафа } \\
\text { на граждан в размере от двадцати тысяч } \\
\text { до тридцати тысяч рублей или обязательные } \\
\text { работы на срок до пятидесяти часов; на } \\
\text { должностных лиц - от двадцати тысяч до } \\
\text { сорока тысяч рублей; на юридических лиц - от } \\
\text { семидесяти тысяч до двухсот тысяч рублей. }\end{array}$ \\
\hline $\begin{array}{l}\text { 3. Действия (бездействие), предусмотренные } \\
\text { частями } 1 \text { и } 2 \text { настоящей статьи, повлекшие } \\
\text { создание помех движению пешеходов или } \\
\text { транспортных средств либо превышение } \\
\text { норм предельной заполняемости территории } \\
\text { (помещения), - }\end{array}$ & $\begin{array}{l}\text { влекут наложение административного штрафа } \\
\text { на граждан в размере от тридцати тысяч до } \\
\text { пятидесяти тысяч рублей или обязательные } \\
\text { работы на срок до ста часов; на должностных } \\
\text { лиц - от пятидесяти тысяч до ста тысяч рублей; } \\
\text { на юридических лиц - от двухсот пятидесяти } \\
\text { тысяч до пятисот тысяч рублей. }\end{array}$ \\
\hline $\begin{array}{l}\text { 4. Действия (бездействие), предусмотренные } \\
\text { частями } 1 \text { и } 2 \text { настоящей статьи, повлекшие } \\
\text { причинение вреда здоровью человека или } \\
\text { имуществу, если эти действия (бездействие) не } \\
\text { содержат уголовно наказуемого деяния, - }\end{array}$ & $\begin{array}{l}\text { влекут наложение административного штрафа } \\
\text { на граждан в размере от ста тысяч до трехсот } \\
\text { тысяч рублей или обязательные работы на } \\
\text { срок до двухсот часов; на должностных лиц - } \\
\text { от двухсот тысяч до шестисот тысяч рублей; } \\
\text { на юридических лиц - от четырехсот тысяч до } \\
\text { одного миллиона рублей. }\end{array}$ \\
\hline
\end{tabular}


статья 20.2 КоАП

Диспозиция

санкция

ответственность участников публичного мероприятия

5. Нарушение участником публичного

мероприятия установленного порядка

проведения собрания, митинга, демонстрации,

шествия или пикетирования, за исключением

случаев, предусмотренных частью 6

настоящей статьи, -

6. Действия (бездействие), предусмотренные

частью 5 настоящей статьи, повлекшие

причинение вреда здоровью человека или

имуществу, если эти действия (бездействие) не

содержат уголовно наказуемого деяния, - влечет наложение административного штрафа в размере от десяти тысяч до двадцати тысяч рублей или обязательные работы на срок до сорока часов.

влекут наложение административного штрафа в размере от ста пятидесяти тысяч до трехсот тысяч рублей или обязательные работы на срок до двухсот часов.

ответственность организаторов и участников публичного мероприятия

7. Организация либо проведение

несанкционированных собрания, митинга,

демонстрации, шествия или пикетирования

в непосредственной близости от территории

ядерной установки, радиационного источника или пункта хранения ядерных материалов и радиоактивных веществ либо активное участие в таких публичных мероприятиях, если это осложнило выполнение работниками указанных установки, источника или пункта своих служебных обязанностей или создало угрозу безопасности населения и окружающей среды, - влечет наложение административного штрафа в размере от ста пятидесяти тысяч до трехсот тысяч рублей или административный арест на срок до пятнадцати суток; на должностных лиц - от двухсот тысяч до шестисот тысяч рублей; на юридических лиц от пятисот тысяч до одного миллиона рублей.";

С одной стороны, основываясь на анализе содержания прежней и новой редакции статьи 20.2 КоАП, можно согласиться с авторами законопроекта о необходимости серьёзной корректировки санкций данной статьи КоАП. Ведь существовавшее правовое регулирование не имело никакой профилактической роли. «Нарушителям предписывался штраф в смехотворном размере, не адекватном содеянному, - в одну тысячу рублей, и они над этим смеялись. Очередное нарушение - и опять такой же штраф по решению суда. Этим и исчерпьвались возможности реагирования». ${ }^{13}$

Однако, с другой стороны, при анализе содержания санкций в статье 20.2 КоАП бросается в глаза их излишний репрессивный характер, который выражается в том, что законодатель фактически предписывает судам Российской Федерации необходимость карать штрафами правонарушителей. ${ }^{14}$ В частности устанавливается нижний предел денежных штрафов, ниже которого суд

13 Тамара Шкель. Правила без исключения. От первого лица: интервью с Владимиром Плигиным. Российская газета. Федеральный выпуск. №5798 (125). http://www.rg.ru/2012/06/04/pligin.html

14 Участие в митинге стало удовольствием для богатых. Петербургский правовой портал «кАДИС». 9 июня 2012 года. http://www.kadis.ru/daily/?id=107656 
не имеет возможности назначить наказание виновным в совершении административного правонарушениия лицам. Оправдано ли такое достаточно строгое правовое регулирование? Представляется, что нет. Именно в санкциях статьи 20.2 КоАП законодателем было заложено противоречие: если в отношении денежных штрафов был установлен нижний (причём очень высокий предел), то в отношении альтернативной санкции - обязательных работ - устанавливается лишь верхний предел. Внимательный читатель обратит внимание на то, что законодатель даёт возможность судам самостоятельно устанавливать количество часов, подлежащих отработке в рамках обязательных работ: во всех частях статьи 20.2 КоАП используется формулировка: «или обязательнье работьл на срок до часов». ${ }^{15}$ Вполне резонно российскому законодателю можно задать вопрос: почему подобное правовое регулирование также не было избрано в отношении регламентации величины штрафов? Ведь фактически отныне суды вынуждены будут штрафовать нарушителей, даже в том числе тогда, когда нарушение малозначительно. А ведь низший предел штрафов, предложенный законодателем, представляет собой большую величину - 10000 рублей (около 250 ЕВРО). Подобная жёсткость и отсутствие внутренней логики ${ }^{16}$ в санкциях статьи 20.2 КоАП всё же не согласуются с основополагающими принципами российской правовой системы: гуманизм и экономия мер государственного принуждения.

Следует также отметить прочие незначительные новшества в праве публичных собраний России, появившиеся в июня 2012 года. В частности, российский федеральный законодатель предложил органам исполнительной власти субъекта Российской Федерации предусмотреть единые специально отведенные или приспособленные для коллективного обсуждения общественно значимых вопросов и выражения общественных настроений, а также для массового присутствия граждан для публичного выражения общественного мнения по поводу актуальных проблем преимущественно общественно-политического характера места (специально отведённые места - см. часть $1^{1}$ статьи 8 Ф3 №54). В отношении данной новеллы, которую правозащитники уже обозначили как создание "резерваций протеста», только со временем можно будет сделать какие-либо выводы. Важно, чтобы при определении перечня специально отведенных мест и установлении порядка их использования представители государственных властей исполняли положения федерального закона о том, что в данных местах должны обеспечиваться возможность дости-

15 Следует отметить, что значительной новеллой в российском административном праве является установление нового вида административного наказания: обязательных работ (статья 3.13 КоАП). Однако, детальный разбор сути и аспектов применения обязательных работ заслуживает отдельного исследования и по этой причине не является предметом рассмотрения в этой статье.

16 Представляется, что законодателю следовало бы, либо убирать «нижний порог» штрафов, либо предусматривать «нижний порог» в отношении количества часов обязательных работ. Подобный противоречивый подход правового регулирования российских законодатель демонстрирует в новой статье $20.2^{2}$ КоАП. 
жения изелей публичных мероприятий, транспортная доступность специально отведенных мест, возможность использования организаторами и участниками публичных мероприятий объектов инфраструктуры, соблюдение санитарных норм и правил, безопасность организаторов и участников публичных мероприятий, других лиц (см. часть $1^{2}$ статьи 8 Ф3 №54).

\section{Заключение}

Вне всякого сомнения необходимость принятия изменений в законодательство России о праве собраний была продиктована самой жизнью, в частности ростом числа публичных мероприятий на всей территории Российской Федерации. Вместе с тем следует избегать как излишней идеализации, так и демонизации предпринятых законодательных изменений. Очевидно, что часть из новелл российского права собраний востребована и вполне согласуется с положениями международного права, а также конституции Российской Федерации. Вместе с тем, есть ряд моментов, которые требуют дальнейшей доработки или даже детальной регламентации. В этой связи следует прогнозировать то, что в ближайшие годы законодательство о праве публичных собраний России претерпит дальнейшие изменения. В частности, следует предположить, что должны появится законодательные нововведения относительно регламентации спонтанных публичных мероприятий, порядка согласования массовых мероприятий (установление стандартной формы уведомления и детализация порядка его подачи, а также прозрачность данного процесса). Несомненно остаётся потребность в детальной регламентации вопросов идентификации полицейских, принимающих участие в публичных мероприятиях. кроме того, учитывая далеко не безупречную юридическую технику, использованную законодателем при корректировке КоАП (переполнение кодекса статьями с пометками «прим»), возможно, что граждан России ожидает принятие нового административного кодекса и кодекса об административном судопроизводстве. ${ }^{17}$

17 Путин предлагает принять кодекс об административном судопроизводстве. РИА-НОВОСТИ. ОБЩЕСТВО. 06.02.12. http://ria.ru/society/20120206/558653058.html 


\section{THE PUBLIC ASSEMBLY (PROTEST) LAW IN MODERN RUSSIA: CONSTITUTIONAL FOUNDATIONS AND PROBLEMS OF IMPLEMENTATION}

The author of the article investigates existing Russian legislation on freedom of assembly and in particular analyzes the latest amendments to Russian law on meetings and demonstrations which were adopted by the Russian Parliament in 2012. The focus point of the research paper is concentrated on the investigation of practical problems by implementation of general provisions of the Russian Public Protest legislation. In the introduction the reader can find information about actual situations in Russia related to the wave of public protest which appeared in 2009-2012. In the main part of the article the hot issues of the Russian Public Assembly (Protest) Law are discussed, especially the new rigorous provisions with regard to the liability of the organizers and participants of public meetings and demonstrations. Attention is also given to the legislative shortcomings (for example with regard to existing legal provisions about notification procedures by the organisers of a public event and the lack of regulations to prevent police violence during public gatherings). The author arrives at the conclusion that the legislative activities in the field of the Russian Public Assembly (Protest) Law will continue in the immediate future.

Key words:

Demonstration, meeting, public protest, assembly, liability, Russia. 